\title{
Generalized Common Fixed Point Theorem in Intuitionistic Fuzzy Metric Space Using Occasionally Converse Commuting Maps
}

\author{
Dr M Ramana Reddy \\ Assistant Professor of Mathematics \\ Sreenidhi Institute of Science and Technology, Hyderabad. \\ mrreddyou@gmail.com
}

\begin{abstract}
In this current article generalized common fixed point theorem in intuitionistic fuzzy metric space using occasionally converse commuting maps .we prove two common fixed point results for assure an embedded family member.
\end{abstract}

Keywords: Intuitionistic fuzzy metric space; occasionally converse commuting (occ); occasionally weakly compatible.

2000 AMS Subject Classification: 47H10; 54H25;

\section{Introduction}

Introduced and studies the concept of intuitionistic fuzzy sets as a overview of fuzzy sets by Atnassov [18]. The notion of intuitionistic fuzzy metric space with the help of continuous t-norms and continuous tconorms as a generalization of fuzzy metric space due to George and Veeramani [4]. Fixed point theory has important applications $\mathrm{n}$ diverse disciplines of mathematics, statistics, engineering, and economics in dealing with problems arising in : Approximation theory, potential theory, game theory, mathematical economics etc. $\mathrm{Lu}[10]$ presented the concept of converse commuting mappings and proved some common fixed point results. Liu and $\mathrm{Hu}$ [9] used this concept for multi-valued mappings. Extended his result for the mappings satisfying an implicit relation by Popa [17] Recently, Pathak et al. [16] introduce the notion of occasionally converse commuting (occ) mappings and prove some fixed point theorems on four self maps by using this concept. [11] The concepts of triangular norms (t-norms) and triangular conforms (t-conorms) are known as the axiomatic skelton that we use are characterization fuzzy intersections and union respectively.

In this paper, we use the notion of occasionally converse commuting (occ) and occasionally weakly compatible mappings in intuitionistic fuzzy metric space. By using this concept, the common fixed point results for a quadruple of self-mappings which satisfy an embedded family member. Our result generalizes the results of Pathak et al. [16] in intuitionistic fuzzy metric space.

\section{Preliminaries}

Definition 2.1 [13]. A binary operation $*:[0,1] \times[0,1] \rightarrow[0,1]$ and $\diamond:[0,1] \times[0,1] \rightarrow[0,1]$ is continuous t-norm if $*$ satisfied the following conditions:

(i) * is commutative and associative;

(ii) * is continuous;

(iii) a $* 1=$ a for all $a \in[0,1]$

(iv) $\mathrm{a} * \mathrm{~b} \leq \mathrm{c} * \mathrm{~d}$ whenever $\mathrm{a} \leq \mathrm{c}$ and $\mathrm{b} \leq \mathrm{d}$ for all $\mathrm{a}, \mathrm{b}, \mathrm{c}, \mathrm{d} \in[0,1]$.and

(i) $\diamond$ is commutative and associative;

(ii) $\diamond$ is continuous;

(iii) a $\diamond 1=$ a for all $a \in[0,1]$

(iv) $\mathrm{a} \diamond \mathrm{b} \leq \mathrm{c} \diamond \mathrm{d}$ whenever $\mathrm{a} \leq \mathrm{c}$ and $\mathrm{b} \leq \mathrm{d}$ for all indent $\mathrm{a}, \mathrm{b}, \mathrm{c}, \mathrm{d} \in[0,1]$.

Definition 2.3 [1]. A 5-tuple $(\mathrm{X}, \mathrm{M}, \mathrm{N}, * \ldots \diamond)$ is said to be an intuitionistic fuzzy metric space if $\mathrm{x}$ is an arbitrary set, $\diamond$ is a continuous t-norm, $\diamond$ is a continuous t-conorm and $\mathrm{M}, \mathrm{N}$ are fuzzy sets on $\mathrm{X}^{2} \mathrm{x}[0, \infty]$ satisfying the following conditions :

(i) $M(x, y, t)+N(x, y, t) \leq 1$ for all $x, y \in X$ and $t>0$;

(ii) $\mathrm{M}(\mathrm{x}, \mathrm{y}, 0)=0$ for all $\mathrm{x}, \mathrm{y} \in \mathrm{x}$;

(iii) $\mathrm{M}(\mathrm{x}, \mathrm{y}, \mathrm{t})=1$ for all $\mathrm{x}, \mathrm{y} \in \mathrm{X}$ and $\mathrm{t}>0$ if and only if $\mathrm{x}=\mathrm{y}$;

(iv) $\mathrm{M}(\mathrm{x}, \mathrm{y}, \mathrm{t})=\mathrm{M}(\mathrm{x}, \mathrm{y}, \mathrm{t})$ for all $\mathrm{x}, \mathrm{y} \in \mathrm{X}$ and $\mathrm{t}>0$;

(v) $\mathrm{M}(\mathrm{x}, \mathrm{y}, \mathrm{t}) * \mathrm{M}(\mathrm{y}, \mathrm{z}, \mathrm{s}) \leq \mathrm{M}(\mathrm{x}, \mathrm{z}, \mathrm{t}+\mathrm{z})$ for all $\mathrm{x}, \mathrm{y} \in \mathrm{X}$ and $\mathrm{s}, \mathrm{t}>0$;

(vi) for all $\mathrm{x}, \mathrm{y} \in \mathrm{X}, \mathrm{M}(\mathrm{x}, \mathrm{y},):.[0, \infty] \rightarrow[0,1]$ is left continuous; 
(vii) $\lim _{n \rightarrow \infty} M(x, y, t)=1$ for all $\mathrm{x}, \mathrm{y} \in \mathrm{X}$ and $\mathrm{t}>0$;

(viii) $\mathrm{N}(\mathrm{x}, \mathrm{y}, 0)=1$ for all $\mathrm{x}, \mathrm{y} \in \mathrm{X}$;

(ix) $N(x, y, t)=0$ for all $x, y \in X$ and $t>0$ if and only if $x=y$;

(x) $N(x, y, t)=N(y, x, t)$ for all $x, y \in X$ and $t>0$;

(xi) $\mathrm{N}(\mathrm{x}, \mathrm{y}, \mathrm{t}) \diamond \mathrm{N}(\mathrm{y}, \mathrm{z}, \mathrm{s})=\mathrm{N}(\mathrm{x}, \mathrm{z}, \mathrm{t}+\mathrm{s})$ for all $\mathrm{x}, \mathrm{y} \in \mathrm{X}$ and $\mathrm{s}, \mathrm{t}>0$;

(xii) for all $\mathrm{x}, \mathrm{y} \in \mathrm{X}, \mathrm{N}(\mathrm{x}, \mathrm{y},):.[0, \infty) \rightarrow[0,1]$ is right continuous;

(xiii) $\lim _{n \rightarrow \infty} N(x, y, t)=1$ for all $\mathrm{x}, \mathrm{y} \in \mathrm{X}$.

Then $(M, N)$ is called an intuitionistic fuzzy metric space on $X$. the functions $M(x, y, t)$ and $N(x, y, t)$ denote the quantity of proximity and the quantity of non-nearness between $\mathrm{x}$ and $\mathrm{y}$ w.r.t $\mathrm{t}$ in that order.

Remark 2.1[1] Every fuzzy metric space $\left(\mathrm{X}, \mathrm{M},{ }^{*}\right)$ is an intuitionistic fuzzy metric space of the form (X, M, 1$\mathrm{M}, *, \diamond)$ such that $\mathrm{t}$-norm * and $\mathrm{t}$-conorm $\diamond$ are associated as $\mathrm{x} \diamond \mathrm{y}=1-\left((1-\mathrm{x})^{*}(1-\mathrm{y})\right)$ for all $\mathrm{x}, \mathrm{y} \in \mathrm{X}$.

Remark 2.2 [1] In intuitionistic fuzzy metric space $\left(\mathrm{X}, \mathrm{M}, \mathrm{N},{ }^{*}, \diamond\right) \mathrm{M}\left(\mathrm{x}, \mathrm{y},{ }^{*}\right)$ is non-decreasing and $\mathrm{N}(\mathrm{x}, \mathrm{y}, \diamond)$ is non-increasing for all $\mathrm{x}, \mathrm{y} \in \mathrm{X}$.

Definition 2.4 [1] Let $(X, M, N, *, \diamond)$ be an intuitionistic fuzzy metric space. Then

(a) a sequence $\left\{\mathrm{x}_{\mathrm{n}}\right\}$ in $\mathrm{X}$ is said to be Cauchy sequence if, for all $\mathrm{t}>0$ and $\mathrm{p}>0$,

$$
\lim _{n \rightarrow \infty} M\left(x_{n+p}, x_{n}, t\right)=1 \text { and } \lim _{n \rightarrow \infty} N\left(x_{n+p}, x_{n}, t\right)=0
$$

(b) a sequence $\left\{\mathrm{x}_{\mathrm{n}}\right\}$ in $\mathrm{X}$ is said to be convergent to a point $\mathrm{x} \mathrm{X}$ if, for all $\mathrm{t}>0, \lim _{n \rightarrow \infty} M\left(x_{n}, x, t\right)=1 \quad$ and $\lim _{n \rightarrow \infty} N\left(x_{n}, x, t\right)=0$

Definition 2.5 [1] An intuitionistic fuzzy metric space (X, M, N, * $)$ is said to be complete if and only if every Cauchy sequence in $\mathrm{X}$ is convergent.

Definition 2.6 [10] A pair of self mappings (A, S) of intuitionistic fuzzy metric space (X, M, N<*, $)$ is said to be conversely commuting if for all $\mathrm{x} \in \mathrm{X}$, the $\mathrm{ASx}=$ Sax implies $\mathrm{Ax}=\mathrm{Sx}$.

Definition 2.7 [16]. A pair of self mappings (A, S) of an intuitionistic fuzzy metric space (X, M, N, * $)$ is said to be occasionally conversely commuting (occ), if for some $\mathrm{x} \in \mathrm{X}$, the ASx $=$ Sax

Implies Ax $=$ Sx.

In 1996, Jungck [5] introduced the notion of weakly compatible maps as follows:

Definition 2.8 [5]. A pair of self mappings (A, S) of a metric space is said to be weakly compatible if they commute at the coincidence points i.e. Ax $=\mathrm{sx}$ for some $\mathrm{x} \in \mathrm{X}$, then $\mathrm{ASx}=\mathrm{SAx}$.

The concept of weakly compatible mapping was generalized to occasionally weakly compatible.

Definition 2.9 [6] A pair of self mappings (A, S) of an intuitionistic fuzzy metric space (X, M, N, *, $\diamond)$ is said to be occasionally weakly compatible (owc) if they commute at coincidence points i.e. $\mathrm{ASx}=\mathrm{Sax}$ whenever $\mathrm{Ax}=$ Sx for some $\mathrm{x} \in \mathrm{X}$.

Note:Every conversely commuting mappings is occ but the reverse need not be true.

Every weakly compatible mapping in owc but not conversely.

\section{Main Results}

Theorem 3.1 Let A, B, S and $\mathrm{T}$ be self mappings of an intuitionistic fuzzy metric space (X, M, N, *, $\diamond)$ satisfying the following (3.1) for any $\mathrm{x}, \mathrm{y} \in \mathrm{X}$, and for all $\mathrm{t}>0$.

$$
\begin{aligned}
& \min \Delta(M(A x, B y, k t), M(S x, T y, t), M(A x, S x, t), M(B y, S x, 2 t), M(A x, T y, t)) \geq 0 \\
& \max \nabla(N(A x, B y, k t), N(S x, T y, t), N(A x, S x, t), N(B y, S x, 2 t), N(A x, T y, t)) \leq 0
\end{aligned}
$$

Where $\nabla . \Delta:[0,1] \rightarrow[0,1]$ is in the class of all continuous mappings satisfying $\Delta(\mathrm{t}, 1,1, \mathrm{t})<0$ and $\nabla(t, 0,0, t)>0$ for all $\mathrm{t} \in(0,1)$ if one of the following conditions holds :

(3.2) the pair $(\mathrm{A}, \mathrm{S})$ is occ and the pair $(\mathrm{B}, \mathrm{T})$ is owc or

(3.3) the pair (B, T) is occ and the pair (A, S) is owc.

Then $\mathrm{A}, \mathrm{B}, \mathrm{S}$ and $\mathrm{T}$ have a unique common fixed point.

Proof: Let $\mathrm{x}_{0}$ be any arbitrary point in $\mathrm{X}$, construct a sequence $\mathrm{y}_{\mathrm{n}} \in \mathrm{X}$ such that $\mathrm{y} 2 \mathrm{n}-1=\mathrm{Tx} 2 \mathrm{n}-1=\mathrm{Ax}_{2 \mathrm{n}-2}$ and $\mathrm{y}_{2 \mathrm{n}}$ $=\mathrm{Sx}_{2 \mathrm{n}}=\mathrm{Bx}_{2 \mathrm{n}-1}, \mathrm{n}=1,2,3 \ldots$ This can be done by the virtue of (i). By contractive condition we obtain,

$$
\begin{aligned}
M\left(y_{2 n+1}, y_{2 n+2}, k t\right)= & M\left(A x_{2 n}, B x_{2 n+1}, k t\right), \\
& \min \Delta\left\{M\left(S x_{2 n}, T x_{2 n+1}, t\right), M\left(B x_{2 n+1}, S x_{2 n}, 2 t\right), M\left(A x_{2 n}, T x_{2 n+1}, t\right)\right\} \geq 0
\end{aligned}
$$




$$
\left.\begin{array}{c}
\min \Delta\left\{\begin{array}{c}
M\left(y_{2 n}, y_{2 n+1}, t\right), M\left(y_{2 n+1}, y_{2 n}, t\right), M\left(y_{2 n+2}, y_{2 n+1}, t\right), \\
M\left(y_{2 n+2}, y_{2 n}, 2 t\right), M\left(y_{2 n+1}, y_{2 n+1}, t\right)
\end{array}\right\} \geq 0 \\
\text { i.e., } M\left(y_{2 n+1}, y_{2 n+2}, k t\right), M\left(y_{2 n}, y_{2 n+1}, t\right) \geq 0
\end{array}\right\} \begin{gathered}
\max \nabla\left\{M\left(S x_{2 n}, T x_{2 n+1}, t\right), N\left(B x_{2 n+1}, S x_{2 n}, 2 t\right), N\left(A x_{2 n}, T x_{2 n+1}, t\right)\right\} \leq 0 \\
\left.y_{2 n+2}, k t\right)=N\left(A x_{2 n}, B x_{2 n+1}, k t\right), \\
\max \nabla\left\{\begin{array}{c}
N\left(y_{2 n}, y_{2 n+1}, t\right), N\left(y_{2 n+1}, y_{2 n}, t\right), N\left(y_{2 n+2}, y_{2 n+1}, t\right), \\
N\left(y_{2 n+2}, y_{2 n}, 2 t\right), N\left(y_{2 n+1}, y_{2 n+1}, t\right)
\end{array}\right\} \leq 0 \\
\text { i.e., } N\left(y_{2 n+1}, y_{2 n+2}, k t\right), N\left(y_{2 n}, y_{2 n+1}, t\right) \leq 0
\end{gathered}
$$

In general $M\left(y_{n}, y_{n+1}, k t\right), M\left(y_{n-1}, y_{n}, t\right) \geq 0, N\left(y_{n}, y_{n+1}, k t\right), N\left(y_{n-1}, y_{n}, t\right) \leq 0$

To prove $\left\{\mathrm{y}_{\mathrm{n}}\right\}$ is a Cauchy sequence, we have to show $M\left(y_{n}, y_{n+1}, t\right) \rightarrow 1, N\left(y_{n}, y_{n+1}, t\right) \rightarrow 1$ (for $\mathrm{t}>0$ as $\mathrm{n} \rightarrow \infty$ uniformly on $\mathrm{p} \in \mathrm{N})$. For this we have,

$$
\begin{gathered}
\min \Delta M\left(y_{n}, y_{n+1}, t\right) \geq M\left(y_{n-1}, y_{n}, t / k\right) \geq M\left(y_{n-2}, y_{n-1}, t / k^{2}\right) \geq \ldots \geq \\
M\left(y_{0}, y_{1}, t / k^{n}\right) \rightarrow 1 \text { as } n \rightarrow \infty \\
\max \nabla N\left(y_{n}, y_{n+1}, t\right) \leq N\left(y_{n-1}, y_{n}, t / k\right) \leq N\left(y_{n-2}, y_{n-1}, t / k^{2}\right) \leq \ldots \leq \\
N\left(y_{0}, y_{1}, t / k^{n}\right) \rightarrow 1 \text { as } n \rightarrow \infty
\end{gathered}
$$

For $\mathrm{p} \in \mathrm{N}$, by (i) we now have

$$
\begin{aligned}
& \min \Delta M\left(y_{n}, y_{n+p}, t\right) \geq M\left(y_{n}, y_{n+1},(1-k) t\right) * M\left(y_{n+1}, y_{n+p}, k t\right) \geq 0 \\
& \min \Delta M\left(y_{0}, y_{1}, \frac{(1-k) t}{k^{n}}\right) * M\left(y_{n+1}, y_{n+2}, t\right) * M\left(y_{n+2}, y_{n+p},(k-1) t\right) \geq 0 \\
& \min \Delta M\left(y_{0}, y_{1}, \frac{(1-k) t}{k^{n}}\right) * M\left(y_{0}, y_{1}, \frac{t}{k^{n}}\right) * M\left(y_{n+2}, y_{n+3}, t\right) \\
& \quad * M\left(y_{n+3}, y_{n+p},(k-2) t\right) \geq 0 \\
& \min \Delta M\left(y_{0}, y_{1}, \frac{(1-k) t}{k^{n}}\right) * M\left(y_{0}, y_{1}, \frac{t}{k^{n}}\right) * M\left(y_{0}, y_{1}, \frac{(1-k) t}{k^{n+2}}\right) \\
& \max \nabla N\left(y_{n}, y_{n+p}, t\right) \leq N\left(y_{n}, y_{n+1},(1-k) t\right) * N\left(y_{n+1}, y_{n+p}, k t\right) \\
& \max \nabla n\left(y_{0}, y_{1}, \frac{(1-k) t}{k^{n}}\right) * N\left(y_{n+1}, y_{n+2}, t\right) * N\left(y_{n+2}, y_{n+p},(k-1) t\right) \leq 0 \\
& \max \nabla N\left(y_{0}, y_{1}, \frac{(1-k) t}{k^{n}}\right) * N\left(y_{0}, y_{1}, \frac{t}{k^{n}}\right) * N\left(y_{n+2}, y_{n+3}, t\right) \\
& * N\left(y_{n+3}, y_{n+p},(k-2) t\right) \leq 0 \\
& \max \leq N\left(y_{0}, y_{1}, \frac{(1-k) t}{k^{n}}\right) * N\left(y_{0}, y_{1}, \frac{t}{k^{n}}\right) * N\left(y_{0}, y_{1}, \frac{(1-k) t}{k^{n+2}}\right) \\
& * \ldots N\left(y_{0}, y_{1}, \frac{(k-p) t}{k^{n+p+1}}\right) \leq 0
\end{aligned}
$$


Thus $M\left(y_{n}, y_{n+p}, t\right) \rightarrow 1, N\left(y_{n}, y_{n+p}, t\right) \rightarrow 1$ (for all $\mathrm{t}>0$ as $\mathrm{n} \rightarrow \infty$ uniformly on $\mathrm{p} \in \mathrm{N}$ ). Therefore $\left\{\mathrm{y}_{\mathrm{n}}\right\}$ is a Cauchy sequence in $\mathrm{X}$. By the completeness of $\mathrm{X}$ there exists a point $\mathrm{z}($ say) in $\mathrm{X}$ such that $\{\mathrm{yn}\} \rightarrow \mathrm{z}$. Also using (i) we have $\left\{\mathrm{Ax}_{2 \mathrm{n}-2}\right\},\left\{\mathrm{Tx}_{2 \mathrm{n}-1}\right\},\left\{\mathrm{Sx}_{2 \mathrm{n}}\right\}$, and $\left\{\mathrm{Bx}_{2 \mathrm{n}-1}\right\} \rightarrow \mathrm{z}$.

Now suppose pair of maps (A, S) is compatible and reciprocally continuous the, we have,

$\mathrm{ASx}_{2 \mathrm{n}} \rightarrow \mathrm{Az}$ and $\mathrm{Sax}_{2 \mathrm{n}} \rightarrow \mathrm{Sz}$ as $\mathrm{n} \rightarrow \infty$

And limn $\rightarrow \infty \mathrm{M}\left(\mathrm{ASx}_{2 \mathrm{n}}, \mathrm{Sax}_{2 \mathrm{n}}, \mathrm{t}\right)=1$ i.e. $\mathrm{Az}=\mathrm{Sz}$.

Since $A(X) \subset T(X)$ there exists a point $\mathrm{u} \in \mathrm{X}$ such that $\mathrm{Az}=\mathrm{Tu}$. Using contractive condition we get, $\min \Delta M(A z, B u, k t), \min \left\{\begin{array}{c}M(S z, T u, t), M(A z, S z, t), M(B u, T u, t), \\ M(B u, S z, 2 t), M(A z, T u, t)\end{array}\right\} \geq 0$ $\min \Delta\{M(A z, A z, t), M(A z, A z, t), M(B u, A z, t), M(B u, A z, 2 t), M(A z, A z, t)\} \geq 0$ $>M(A z, B u, t)$, i.e., $\mathrm{Az}=\mathrm{Bu}$.

$\max \nabla N(A z, B u, k t), \max \left\{\begin{array}{c}N(S z, T u, t), N(A z, S z, t), N(B u, T u, t), \\ N(B u, S z, 2 t), N(A z, T u, t)\end{array}\right\} \leq 0$

$\max \nabla\{N(A z, A z, t), N(A z, A z, t), N(B u, A z, t), N(B u, A z, 2 t), N(A z, A z, t)\} \leq 0$

$<N(A z, B u, t)$, i.e., $\mathrm{Az}=\mathrm{Bu}$.

Thus $\mathrm{Sz}=\mathrm{Az}=\mathrm{Tu}=\mathrm{Bu}$. Since $\mathrm{A}$ is point wise s-absorbing, there exist $\mathrm{R}>0$, such that,

$\min \Delta M(S z, S A z, t) \geq M(S z, A z, t / R)=1$, i.e., $\mathrm{Az}=\mathrm{SAz}=\mathrm{Sz}$.

$\max \nabla N(S z, S A z, t) \leq N(S z, A z, t / R)=1$, i.e., $\mathrm{Az}=\mathrm{SAz}=\mathrm{Sz}$.

Again by contractive condition, we have

$$
\begin{aligned}
& \min \Delta M(S z, A A z, k t)=M(A A z, B u, k t) \\
& \min \Delta\{M(S A z, T u, t), M(A A z, S A z, t), M(B u, T u t), M(B u, S A z, 2 t), M(A A z, T u, t)\} \geq 0 \\
& =\min \Delta\{M(A z, A z, t), M(A A z, A z, t), M(B u, B u, t), M(A z, A z, 2 t), M(A A z, A z, t)\} \geq 0 \\
& =M(A A z, A z, t) \\
& \max \nabla N(S z, A A z, k t)=N(A A z, B u, k t) \\
& \max \nabla\{N(S A z, T u, t), N(A A z, S A z, t), N(B u, T u t), N(B u, S A z, 2 t), N(A A z, T u, t)\} \leq 0 \\
& =\max \nabla\{N(A z, A z, t), N(A A z, A z, t), N(B u, B u, t), N(A z, A z, 2 t), N(A A z, A z, t)\} \leq 0 \\
& =N(A A z, A z, t)
\end{aligned}
$$

i.e., $\mathrm{AAz}=\mathrm{Az}=\mathrm{SAz}$. Therefore $\mathrm{Az}$ is a common fixed point of A and s. Similarly, B is point wise t-absorbing, there exist $\mathrm{R}>0$ (not necessarily the same as above, such that,

$$
\begin{aligned}
& \max \Delta M(T u, T B u, t) \geq M(T u, B u, t / R)=1, \text { i.e., } \mathrm{Tu}=\mathrm{TBu}=\mathrm{Bu} . \\
& \max \nabla N(T u, T B u, t) \leq N(T u, B u, t / R)=1, \text { i.e., } \mathrm{Tu}=\mathrm{TBu}=\mathrm{Bu} .
\end{aligned}
$$

Using contractive condition, we have,

$$
\begin{aligned}
& \min \Delta M(B B u, B u, k t)=M(A z, B B u, k t) \\
& =\min \Delta\{M(S z, T B u, t), M(A z, S z, t), M(B B u, T B u, t), M(B B u, S z, 2 t), M(A z, T B u, t)\} \geq 0 \\
& =\min \Delta\{M(S z, B u, t), M(A z, A z, t), M(B B u, B u, t), M(B B u, B u, 2 t), M(A z, B u, t)\} \geq 0 \\
& =M(B B u, B u, t), \text { i.e., } \mathrm{BBu}=\mathrm{Bu}=\mathrm{TBu} . \\
& \max \nabla N(B B u, B u, k t)=N(A z, B B u, k t) \\
& =\max \nabla\{N(S z, T B u, t), N(A z, S z, t), N(B B u, T B u, t), N(B B u, S z, 2 t), N(A z, T B u, t)\} \leq 0 \\
& =\max \nabla\{N(S z, B u, t), N(A z, A z, t), N(B B u, B u, t), N(B B u, B u, 2 t), N(A z, B u, t)\} \leq 0 \\
& =N(B B u, B u, t), \text { i.e., BBu = Bu=TBu.}
\end{aligned}
$$

Therefore $\mathrm{Bu}=\mathrm{Az}$ is a common fixed point of $\mathrm{A}, \mathrm{B}, \mathrm{S}$ and $\mathrm{T}$. Uniqueness of Az easily follows from contractive condition (ii). The proof is similar when pair of mappings (B, T) is assumed as compatible and reciprocally continuous. 


\section{References}

[1] C.Alaca, D.Turkoflu, and C.Yildiz, Fixed points in intuitionistic fuzzy metric spaces, Chaos, Solitions and Fractals, 29 (2006), 1073-1078.

[2] K.Atanassov, Intuitionistic fuzzy sets, fuzzy sets and Systems 20 (1986), 87-96.

[3] D.Coker, An introduction to Intuitionistic Fuzzy topological Spaces, Fuzzy sets and System, 88 (1997), 81-89.

[4] A.George and p.Veeramani, On some results in fuzzy metric spaces, Fuzzy Sets and Systems 64 (1994), 395-399.

[5] G.Jungck, Common Fixed Points for Non-continuous non-self Mappings on a non-numeric Spaces, Far East J.Math. Sci. 4(2) 1996, $199-215$.

[6] G.Jungck and B.E.Rhoades, Fixed Point Theorems for occasionally weakly compatible mappings, fixed point theory, 7(2) (2006), 286-296.

[7] I.Kramosil and J.Michalek, Fuzzy Metric and Statistical Metric Spaces, Kybernetica 11 (1975), 336-344.

[8] S.Kumar, r.K. Vats, V.Singh and S.K. Garg, Some Common Fixed Point Theorems in Intuitionistic fuzzy metric Spaces, Int. Journal of Math. Analysis, 4 (26) (2010), 1255-1270.

[9] Q.K.Liu and x.Hu, Some new common fixed point theorems for converse commuting multi-valued mappings in symmetric spaces with applications, Non linear Analysis Forum 10 (1) (2005), 97-104.

[10] Z.Lu, On common fixed points for converse commuting self-maps on a metric spaces, Acta. Anal. Funct. Appl. 4(3) (2002), 226228.

[11] K.Menger, Statistical metrics, Proc. Nat. Acad. Sci. (USA), 28 (1942), 535-537.

[12] J.H.Park, Intuitionistic Fuzzy metric spaces, Chaos, Solitons and Fractals 22 (2004), 1039-1046.

[13] B.Scheweizer an dA.Sklar, Probabilistic Metric Spaces, North Holland Amsterdam, 1983.

[14] H.K.Pathak and R.K.Verma, Integral type contractive condition for converse commuting mappings, Internat. J. Math. Anal. 3(24) (2009), 1183-1190.

[15] H.K. Pathak and R.K. Verma, An Integral type implicit relation for converse commuting mappings, Internat. J.Math. Anal 3(24) (2009), 1191-1198.

[16] H.K. Pathak and R.K. Verma, Common fixed point theorems for occasionally converse commuting mappings in symmetric spaces, Kathmandu university journal of science, 7(1) (2011), 56-62.

[17] V.Popa, A general fixed point theorem for converse commuting multi-valued mappings in symmetric spaces, Filomat 21(2) (2007), 267-271.

[18] L.A.Zadeh, Fuzzy sets, Infor. And Control, 8 (1965), 338-353. 